\title{
El emprendedor: una aproximación a su definición y caracterización ${ }^{1}$ The entrepreneur: An approach to its definition and characterization
}

Recibido: 19 de octubre de 2012

Evaluado: 18 de febrero de 2013

Aceptado: 15 de marzo de 2013

\author{
Carmen Estela Herrera Guerra (Colombia) \\ Candidata a Magíster en Administración \\ Universidad Nacional de Colombia, sede Bogotá \\ cherrera-44@hotmail.com
}

\section{Luz Alexandra Montoya Restrepo (Colombia)}

Ph.D, Profesora Asociada, Coordinadora Nacional del Concurso Docente, Vicerrectoría General, Grupo de Investigación en Mercadeo, Innovación y Competitividad en Gestión Agropecuaria (Milagro). Universidad Nacional de Colombia, sede Bogotá lamontoyar@unal.edu.co

\section{Resumen}

El emprendimiento como campo de investigación se encuentra en proceso para consolidar un escenario conceptual; muchos estudios giran alrededor de la empresa, desconociendo a la persona, y al emprendimiento se le nombra en la literatura como entrepreneur, conservando este término su origen francés por la inadecuada traducción a otros idiomas. Esta problemática motiva la realización de una revisión bibliográica con el objetivo de recopilar y sistematizar los conceptos emitidos por diferentes autores acerca de la definición y caracterización del emprendedor, lo que servirá de soporte para futuras investigaciones. El documento se desarrolla en tres secciones: la primera, trata del emprendimiento como campo de investigación, su legitimidad, producción literaria, y el emprendi-

\section{Abstract}

Entrepreneurship as a field of research is on its way to consolidate a conceptual stage, many studies revolve around the company (Shane and Venkataraman, 2000; Gámez, 2008, Murphy, 2009), ignoring the person, and entrepreneurship is addressed in literature as entrepreneur (Formichella, 2004; Moncayo, 2008; Gamez, 2008; Castillo, 1999, Gonzalez et al., 2010), this term keeps its French origin due to inadequate translation into other languages. This problem motivates the realization of a literature review in order to collect and systematize the concepts expressed by different authors about the definition and characterization of the entrepreneur, which will support future research. The document is divided into three sections: the first is the entrepreneurship as a 
miento en Asia Pacífico; en la segunda parte se sistematizan los aportes de cada autor; finalmente, se ofrecen las conclusiones.

Palabras clave: emprendimiento, campo de investigación, Asia Pacífico, emprendedor, caracterización. research field, its legitimacy, literary production, and entrepreneurship in Pacific Asia; in the second part we systematize the contributions from each author, and finally the conclusions are presented.

Keywords: entrepreneurship, field of research, Pacific Asia, entrepreneur, characterization. 


\section{Introducción}

En la sociedad contemporánea, la estrategia utilizada por los países y regiones en desarrollo es el fomento de su capacidad competitiva a través de la innovación (Loilier y Tellier, 1999, citado por Aktouf, 2009), la capacidad emprendedora y la flexibilidad del sistema productivo (Díaz et al., 2005), con el fin de conseguir una ventaja competitiva con relación a otros países y regiones (Porter, 1991, citado por Díaz et al., 2005; Porter y Stern, 2001, citados por Aktouf, 2009). Algunos autores se aventuran a decir que se vive en la era de la iniciativa empresarial (Aidar, 2007 y Dornelas, 2008, citados por Mello et al., 2011).

En efecto, el creciente interés que se ha despertado por la creación de empresas como vía de solución a los problemas del desempleo (David Birch, citado por: Varela, 2001; Díaz et al., 2005; Reynolds et al., 2005; Moncayo, 2008; Barros y Pereira, 2008, citados por Mello et al., 2011), del desarrollo económico y regional, y del fomento de la innovación, ha llevado a organizaciones públicas y privadas de todos los países a arbitrar medidas y programas de apoyo a la creación de empresas (Shapero, 1985; Thornton, 1999; Díaz et al., 2005; Amorós, 2011; Sánchez y Gutiérrez, 2011).

Es relevante colocar la mirada en el campo del emprendimiento, y mucho más en la persona que posee la actitud emprendedora, la cual genera nuevos negocios y el crecimiento de unidades empresariales (Moncayo, 2008; Vera y Mora, 2011) y activa el capital humano e intelectual (Shane et al., 2003; Aktouf, 2009). Por esto, el presente documento recopila y sistematiza los principales conceptos emitidos por cada autor, respecto a la definición y caracterización del emprendedor, permitiéndole al lector una mayor comprensión de cada uno de sus planteamientos, y la identificación con ellos.

\section{Metodología}

La investigación universitaria genera diferentes productos que resumen sus resultados y recomendaciones (Rosado, 2008, citado por Vera y Mora, 2011). Este documento presenta una revisión literaria bajo un enfoque cualitativo, de tipo exploratorio y descriptivo, que tiene como objetivo revisar los artículos académicos publicados en el campo del emprendimiento, utilizando como fuente los diarios y revistas o journals, libros, ponencias y artículos disponibles en las bases electrónicas de datos Emerald, Jstor, Ebsco Hot, e-libro, entre otras revistas indexadas por el Departamento Administrativo de Ciencia, Tecnología e Innovación (Colciencias), a fin de tener una aproximación a la definición y caracterización del emprendedor.

El tema se desarrolla en tres secciones: la primera hace referencia al emprendimiento como campo de investigación, su legitimidad y análisis bibliométrico; en la segunda sección se desarrollan las diferentes definiciones y la caracterización del emprendedor, para ello se seleccionaron y sistematizaron los autores más representativos; y finaliza con unas breves conclusiones y desafíos. 


\section{El emprendimiento como campo de investigación}

El emprendimiento, o entrepreneurship, es un área del conocimiento nueva en el ámbito global de la investigación (Matiz, 2009); a partir de los años ochenta la creación de empresas comenzó a tomar un importante auge como campo de investigación científica (Stevenson y Jarillo, 1990; Bygrave y Hofer, 1991; Díaz et al., 2005), razón por la cual es frecuente que se piense que no hay un acuerdo acerca del objeto de investigación en este campo (Bruyat-Julien, 2000, citado por Matiz, 2009).

Las investigaciones en emprendimiento han adoptado teorías de otras disciplinas y las han adaptado para diversos fenómenos del emprendimiento (Shane y Venkataraman, 2000; Díaz et al., 2005; Zahra, 2006, citado por Matiz, 2009; Murphy, 2009), característica que facilita el intercambio intelectual con otras áreas de la gestión pero que a su vez dificulta el desarrollo de la teoría del emprendimiento y la legitimidad de esta (Busenitz et al., 2003, citado por Matiz, 2009).

Es así como, a lo largo del tiempo han surgido teorías del emprendimiento; tanto así, que algunas veces es descrito como una subdisciplina de la estrategia, por lo cual puede decirse que no se ha logrado acordar una sola definición de él (Reynolds et al., 2005; Mello et al., 2011), pero todas las definiciones se complementan. Los trabajos de investigación sobre el emprendimiento se han multiplicado durante los últimos años, aunque se ha desarrollado poco el análisis de la génesis del proyecto del emprendedor (Rodríguez y Jiménez, 2005).
A partir de los años ochenta la promesa de un paradigma teórico diferente ha persistido (Bygrave y Hofer, 1991) y la creación de empresas está tomando un importante auge como campo de investigación científica. Desde distintas ramas de las ciencias sociales (psicología, gestión estratégica, sociología, antropología y psicología social) se analizan los tipos de personas, las formas de explicar diferentes fenómenos empresariales (Shane y Venkataraman, 2000; Murphy, 2009) y se plantea que los empresarios a la hora de decidir crear una empresa se verán influenciados por los factores del entorno (Thornton, 1999; Lounsbury y Glynn, 2001; Díaz et al., 2005).

Resulta interesante tener en cuenta que, además de la riqueza publicada de la que se dispone en el campo del emprendimiento, los académicos que han trabajado en este campo vienen realizado una serie de aportaciones prácticas de enorme riqueza y extraordinaria utilidad (Ronstadt, 1987; Nueno, 2009). El concepto del venture capital (capital riesgo) tiene su origen en el mundo académico (Nueno, 2009) y hoy se ha convertido para la industria a nivel mundial en una ayuda fundamental para que los emprendedores concreten sus ideas y puedan ponerse en contacto con posibles financiadores (Gartner, 1985; Stevenson y Jarillo, 1990; Bygrave y Hofer, 1991; Cable y Shane, 1997; Thornton, 1999; Zahra y Nambisan, 2011).

\section{Legitimidad de las teorías emprendedoras}

El emprendimiento como campo de estudio no es mayor de 30 años, pero se ha desarrollado significativamente durante este período de tiempo. Pese a esto, el 
conocimiento está bastante fragmentado, debido a la falta de un marco conceptual (Venkataraman, 1997, citado por Shane y Venkataraman, 2000; Sánchez y Gutiérrez, 2011), y los débiles fundamentos conceptuales, que disminuyen su contribución a la ciencias de gestión (Grégoire et al., 2011). Es así como ha luchado desde la década de los setenta para definirse como un campo y ganar legitimidad como un área válida académica de la investigación (Cooper, 2003, citado por Acs y Audretsch, 2003).

Bygrave y Hofer (1991, p. 13) inician su artículo indicando que hacia la década de los ochenta el emprendimiento fue en el mejor de los casos un campo prometedor de la investigación académica. Sin embargo, a finales de esa década, debido principalmente a los impresionantes avances en su cuerpo de conocimiento empírico, el emprendimiento pretende ser un campo legítimo de la investigación académica en todos los aspectos (Stevenson y Jarillo, 1990), excepto en uno: le falta una parte sustancial de fundamentación teórica.

Con todo, el emprendimiento es una gran promesa como área distinta de la investigación (Murphy, 2009), en la que se espera la unión de otros investigadores eruditos en diferentes campos para lograr crear un cuerpo sistemático de información sobre el emprendimiento y de esta forma mostrar a los escépticos que es posible la creación y posterior ensamble de un cuerpo de teoría al respecto (Shane y Venkataraman, 2000).

\section{Análisis bibliométrico en emprendimiento}

Casson (1982, p. xiii, citado por Stevenson y Jarillo, 1990, p. 22) ha señalado que la tarea de revisar la literatura sobre el emprendimiento se vuelve sumamente difícil por el hecho de que en la mayoría de los estudios académicos no aparece la palabra 'empresario' en los títulos, mientras que la mayor parte de la literatura con el título 'empresario' no es académica, o no todo trata del empresario debidamente. Algunos trabajos hacen referencia al estudio bibliométrico en el campo del emprendimiento (Kent, 1989; Van y Versloot, 2007; Matiz, 2009; Kuskova et al., 2011; Sánchez y Gutiérrez, 2011).

Para realizar el análisis bibliométrico se toma como fuente la base de datos Scopus, con fecha 24 de mayo de 2012, indicando en la ecuación de búsqueda la palabra 'entrepreneurship', lo cual arrojó una serie de datos desde 1958 hasta la fecha de consulta, sobre los autores, asociaciones y países con más publicaciones sobre el tema, por lo cual en este documento solo se referencian los diez primeros resultados sobre las dimensiones de año, autor, asignatura, tipo de documento, título en los journals, asociación, país e idioma, con la respectiva publicación. Los resultados presentados en la tabla no guardan ninguna relación de forma horizontal, dado que solo se presenta la dimensión con su publicación en orden vertical.

De acuerdo con las cifras reportadas en la base de Scopus, se clasificó la información en el cuadro 1, evidenciándose que, a partir de 2009 hasta esta fecha, el número de publicaciones sobre el emprendimiento se ha incrementado de forma significativa, pasando de 862 publicaciones en 2008 a 1024 en 2009 y 1497 en 2011, lo que refleja un mayor interés por parte de los investigadores en este tema.

El autor más destacado es David Audretsch, con 47 publicaciones, seguido 
por Shane Scott, Zahra Shaker y Acs Zoltan J., con 28 publicaciones cada uno. Las asignaturas en la cuales se presentan más publicaciones sobre el emprendimiento son Negocios, Administración y Contaduría, con 4699, seguida de Ciencias Sociales con 2723, y Economía, Econometría y Finanzas con 2639 publicaciones.
El tipo de documento más utilizado para publicar sobre el emprendimiento es el artículo en revistas indexadas, con 7493 publicaciones, seguida de las memorias ofrecidas después de una conferencia, con 1260 y las reseñas críticas, con 977.

Tabla 1. Análisis de año, autores, asignatura y tipo de documento por publicación

\begin{tabular}{|c|c|c|c|c|c|c|c|}
\hline Año & $\begin{array}{l}\text { N. } \\
\text { Pub. }\end{array}$ & Autor & $\begin{array}{l}\text { N. } \\
\text { Pub. }\end{array}$ & Asignatura & N. ${ }^{\circ}$ Pub. & $\begin{array}{l}\text { Tipo de docu- } \\
\text { mento }\end{array}$ & $\begin{array}{l}\text { N. } \\
\text { Pub. }\end{array}$ \\
\hline 2013 & 2 & $\begin{array}{l}\text { Audretsch, } \\
\text { D. B. }\end{array}$ & 47 & $\begin{array}{l}\text { Negocios, Administración y } \\
\text { contabilidad }\end{array}$ & 4699 & Artículo & 7493 \\
\hline 2012 & 481 & Shane, S. & 28 & Ciencias Sociales & 2723 & $\begin{array}{l}\text { Artículo de } \\
\text { conferencia }\end{array}$ & 1260 \\
\hline 2011 & 1497 & Zahra, S. A. & 28 & $\begin{array}{l}\text { Economía, Econometría y } \\
\text { finanzas }\end{array}$ & 2639 & Reseña & 977 \\
\hline 2010 & 1322 & Acs, Z. J. & 27 & Ingeniería & 1141 & Sin definir & 243 \\
\hline 2009 & 1024 & Nijkamp, P. & 24 & Medicina & 791 & Artículo en prensa & 220 \\
\hline 2008 & 862 & Wright, M. & 24 & Ciencias ambientales & 501 & Editorial & 174 \\
\hline 2007 & 794 & Urbano, D. & 23 & Informática & 483 & Encuesta corta & 125 \\
\hline 2006 & 704 & Dana, L. P. & 21 & Sin definir & 438 & Nota & 111 \\
\hline 2005 & 634 & Welter, F. & 21 & Ciencias de la Decisión & 383 & $\begin{array}{l}\text { Reseña de } \\
\text { conferencia }\end{array}$ & 35 \\
\hline 2004 & 451 & Ireland, R. D. & 20 & Psicología & 285 & Carta & 28 \\
\hline
\end{tabular}

Tomado de Scopus.

Los tres journals que más titulares tienen en el tema de emprendimiento son: Journal of Business Venturing, con 320 artículos; Small Business Economics, con 281, y el International Journal of Entrepreneurship and Small Business, con 214 artículos.

Las tres asociaciones que más publican en emprendimiento son: Indiana University, 127 artículos; Max-Planck-Institut für Ökonomik, 96, y George Mason University, 88.

El país que más publica sobre el emprendimiento es Estados Unidos, con un total de 3072 publicaciones, seguido del Reino Unido, con 1127. Por lo tanto, no es de extrañar que el idioma más utilizado sea el inglés, en 10473 artículos, seguido del español, en tan solo 98 publicaciones (ver tabla 2). 
Tabla 2. Análisis de título en los journal, asociación, país e idioma por publicación

\begin{tabular}{|c|c|c|c|c|c|c|c|}
\hline Título en los journals & $\begin{array}{l}\text { N. } \\
\text { Pub. }\end{array}$ & Asociación & $\begin{array}{l}\text { N. } \\
\text { Pub. }\end{array}$ & País & $\begin{array}{l}\text { N. } \\
\text { Pub. }\end{array}$ & Idioma & $\begin{array}{l}\text { N. } \\
\text { Pub. }\end{array}$ \\
\hline $\begin{array}{l}\text { Journal of Business } \\
\text { Venturing }\end{array}$ & 320 & $\begin{array}{l}\text { Indiana } \\
\text { University }\end{array}$ & 127 & $\begin{array}{l}\text { Estados Uni- } \\
\text { dos }\end{array}$ & 3072 & Inglés & 10473 \\
\hline Small Business Economics & 281 & $\begin{array}{l}\text { Max-Planck- } \\
\text { Institut für } \\
\text { Ökonomik }\end{array}$ & 96 & Reino Unido & 1127 & Español & 98 \\
\hline $\begin{array}{l}\text { International Journal of } \\
\text { Entrepreneurship and } \\
\text { Small Business }\end{array}$ & 214 & $\begin{array}{l}\text { George Mason } \\
\text { University }\end{array}$ & 88 & Alemania & 473 & Francés & 75 \\
\hline Nature Biotechnology & 195 & $\begin{array}{l}\text { Erasmus } \\
\text { University } \\
\text { Rotterdam }\end{array}$ & 68 & Canadá & 422 & Alemán & 72 \\
\hline $\begin{array}{l}\text { ASEE Annual Conference } \\
\text { and Exposition } \\
\text { Conference Proceedings }\end{array}$ & 181 & Babson College & 61 & Países Bajos & 337 & Portugués & 43 \\
\hline $\begin{array}{l}\text { Entrepreneurship Theory } \\
\text { and Practice }\end{array}$ & 171 & $\begin{array}{l}\text { Rensselaer } \\
\text { Polytechnic } \\
\text { Institute }\end{array}$ & 55 & China & 335 & Chino & 27 \\
\hline $\begin{array}{l}\text { Entrepreneurship and } \\
\text { Regional Development }\end{array}$ & 147 & $\begin{array}{l}\text { Stanford } \\
\text { University }\end{array}$ & 55 & España & 295 & Croata & 24 \\
\hline $\begin{array}{l}\text { International } \\
\text { Entrepreneurship and } \\
\text { Management Journal }\end{array}$ & 119 & $\begin{array}{l}\text { University of } \\
\text { Maryland }\end{array}$ & 53 & Australia & 290 & Checo & 20 \\
\hline $\begin{array}{l}\text { Journal of Small } \\
\text { Business and Enterprise } \\
\text { Development }\end{array}$ & 98 & $\begin{array}{l}\text { Case Western } \\
\text { Reserve } \\
\text { University }\end{array}$ & 52 & Suecia & 271 & Ruso & 20 \\
\hline $\begin{array}{l}\text { International Journal of } \\
\text { Entrepreneurship and } \\
\text { Innovation Management }\end{array}$ & 91 & $\begin{array}{l}\text { Nueva York } \\
\text { University }\end{array}$ & 52 & Francia & 163 & Ucraniano & 19 \\
\hline
\end{tabular}

Tomado de Scopus.

\section{El emprendimiento en Asia Pacífico}

Asia es una región heterogénea, con países que difieren en sus niveles de actividad empresarial, económica y exportadora. Por ejemplo, al medir el producto interno bruto (PIB) per cápita de Japón, Singapur y Australia, estos resultan muy ricos, mientras que países como India, Indonesia y Filipinas resultan relativamente pobres (Dana, 2007, citado por Terjesen y Hessels, 2009).
A continuación, se presenta la ubicación geográfica de estos países, teniendo en cuenta que la expresión cuenca del $\mathrm{Pa}$ cífico es utilizada en el entorno político y académico para demarcar un área geográfica compuesta por los países de Asia Pacífico y América Latina (ver figura 1). 
Figura 1. Países centrales de

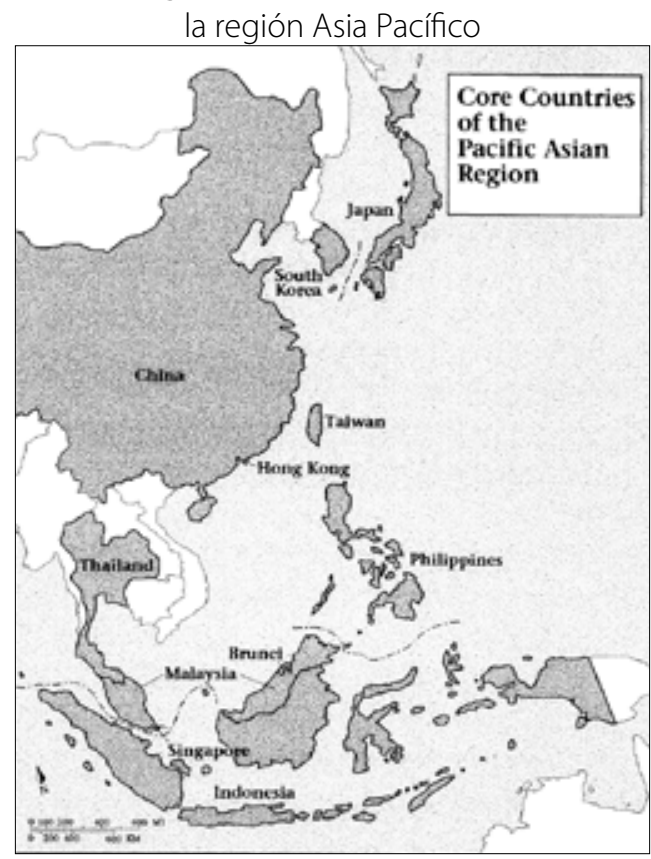

Tomado de Murphy (1995) (Asia Pacífico).

El emprendimiento es uno de los motores utilizados para el crecimiento de las economías desarrolladas y en desarrollo, especialmente en Asia, donde los empresarios buscan introducir innovaciones que se valoricen tanto en sus países de origen como en el extranjero (Terjesen y Hessels, 2009), motivo por el cual Asia Pacífico es reconocida como una de las potencias de la nueva economía mundial, resaltando la participación de Japón y China (Murphy, 1995; Kshetri y Dholakia, 2011; Wielemaker y Gedajlovic, 2011).

En la actualidad las empresas asiáticas imitan a sus homólogas de las economías avanzadas de Europa y Estados Unidos. Mediante alianzas estratégicas con empresas conjuntas (joint ventures), fabricación de equipos originales (OEM), o contratos específicos de abastecimiento han ido adquiriendo rápidamente conocimientos críticos y tecnologías, permitiendo que empresas como Acer, Haier, Huawei, Hutchison Whampoa, Hyundai, Lenovo y Samsung se hayan convertido en actores globales gracias a su rápido crecimiento durante los últimos treinta años (Lu et al., 2008).

Durante las últimas décadas, y bajo la influencia ideológica de un mercado global, el pensamiento centrado en la Administración Pública ha sido reemplazado en el sudeste de Asia con teorías sesgadas al mercado. Esta tendencia de gobierno refleja el renacimiento mundial de un estilo neoclásico, actualizado con lenguajes como joint venture, asociación, calidad de servicio, satisfacción del cliente ( $\mathrm{Ha}-$ que, 2004). En China, el Gobierno genera un ambiente institucional propicio para la creación y explotación de oportunidades (Phan et al., 2010; Gupta et al., 2012), mientras que Australia posee un sistema de innovación relativamente débil, por la falta de financiación, conocimiento y el uso de incubadoras (Milton, 2001).

Asociado con el surgimiento de las economías de Asia Pacífico, Japón y los cuatro pequeños dragones (Hong Kong, Singapur, Corea del Sur y Taiwán) desde 1960 hasta 1980, China y la India han atraído una atención internacional considerable por sus altas tasas de crecimiento del PIB en los últimos veinte años (Lu et al., 2008). Sin embargo, la mayoría de los artículos nombran al Asia Pacífico o China como opción de contexto, antes que a la India, a pesar de la amplia cobertura que se le ha dado por parte de los medios de comunicación en los últimos años (Pleggenkuhle-Miles et al., 2007).

Una de las tendencias más importantes en la región Asia Pacífico es la rápida difusión de Internet y el crecimiento 
del mercado de las aplicaciones de comercio electrónico, ya que esta región intenta utilizar la red para comercializar sus productos como un medio que le permita obtener una ventaja competitiva en el mercado global (Wood, 2004; Lu et al., 2008), lo que llevó a los Gobiernos asiáticos a aumentar las inversiones en capital humano y tecnología con las cuales construir estructuras que apoyen la búsqueda de oportunidades de alto crecimiento empresarial (Terjesen y Hessels, 2009).

Es importante conocer la dinámica del emprendimiento en los países de la región del Asia Pacífico, por la importancia que tienen en el comercio mundial, las exportaciones y los tratados de libre comercio, los cuales han activado favorablemente la economía de América Latina durante los últimos ańos, pues representan una fuente de capital importante a través de la inversión extranjera, así como una motivación para los emprendedores de fortalecer vínculos que mejoren y faciliten las relaciones económicas.

\section{Aproximación a la definición y caracterización del emprendedor}

Existen varias teorías acerca del emprendimiento; en sí los primeros estudios sobre el emprendedor hay que situarlos históricamente a finales del siglo XIX y principios del XX. Sin embargo, debe aclararse que no hay consenso sobre la teoría empresarial, pero sí se ha generado una variedad de aportes sobre el emprendedor (Flor y Lara, 2012).

Actualmente se han dado varios enfoques investigativos que abordan las teorías del emprendimiento: desde la psicología social, que asume que los empresarios son individuos con rasgos diferentes a los del resto de la sociedad (psicológicos: motivación, carácter; biográficos: orígenes familiares y sociales, educación, experiencia); los que hacen referencia a las condiciones del entorno: económicofinancieros, geográficos, institucionales, funcionamiento de los mercados, sistemas de educación y de ciencia y tecnología, valores predominantes en la sociedad), determinantes en la creación empresarial; y un tercer enfoque ecléctico, que considera tanto los rasgos psicológicos y biográficos como los factores del entorno (Gartner, 1985; Stevenson y Jarillo, 1990; Valdaliso y López, 2000).

En este trabajo, las diversas teorías asociadas al emprendedor y su función serán abordadas y sistematizadas de acuerdo con la siguiente categorización: los clásicos, los neoclásicos, la escuela de Schumpeter, la escuela austriaca, las escuelas del pensamiento según Fonrouge (2002), y otros aportes al tema del emprendedor realizados por diferentes autores.

\section{Definición del emprendedor}

Emprender es un término que tiene múltiples acepciones, según el contexto en el que sea empleado; se encuentran varias maneras de definirlo y entenderlo, pero, muchos autores coinciden en que dicho vocablo se deriva de entrepreneur, que a su vez se origina del verbo francés entreprendre, que significa "encargarse de" (Moncayo, 2008), empleado para designar a los responsables de expediciones militares. En Inglaterra los emprendedores recibieron diversos nombres, como: undertakers, adventurers y projectors (Valdaliso y López, 2000). En el Reino Unido 
entrepreneur es quien dirige una empresa o es empresario, mientras que en Estados Unidos y Canadá es quien negocia o financia negocios, los dirige u organiza. En inglés las acepciones de entrepreneur aluden al productor (producer). En francés, es el hombre de empresa (Gámez, 2008).

Como se comentaba al inicio, la palabra emprendedor proviene del francés entrepreneur (pionero), utilizada inicialmente para referirse a aventureros que, como Colón, arribaron al Nuevo Mundo sin saber con certeza qué esperar en él. Hoy en día, esta misma actitud hacia la incertidumbre es lo que caracteriza al emprendedor. Posteriormente fue usado el término para identificar a quien comenzaba una empresa, y fue ligado a empresarios innovadores (Castillo, 1999; González et al., 2010), especialmente a quienes comienzan una empresa comercial, pero también puede relacionarse con cualquier persona que decida llevar adelante un proyecto, aunque este no tenga fines económicos (Formichella, 2004).

Actualmente se hace distinciones entre el emprendedor, el inversionista y el empresario. Así, Zorrilla (2009) hace referencia a ellos así: emprendedor, quien tiene la idea, el concepto, de un producto o servicio a realizar; inversionista, quien pone a disposición el capital necesario para el sostenimiento inicial y la puesta en marcha del negocio; $y$, finalmente y no menos importante, el empresario, es la persona que se encargar de administrar $\mathrm{y}$ rendir cuentas del negocio.

También se hace necesario enfatizar que no existe una receta única y mágica que a todos les dé el mismo resultado, puesto que las personas pueden tomar decisiones diferentes cuando se enfrentan a las mismas oportunidades, siendo los factores externos un papel importante en las decisiones a tomar (Shane et al., 2003). Otros afirman que "cada cabeza es un mundo" y por lo tanto cada quien pensamos y nos comportamos de manera distinta (Zorilla, 2009).

El conocimiento y la forma que toma un significado en un contexto particular puede llegar a perder su sentido y valor cuando se retira de la configuración original (Zahra y Nambisan, 2011), lo cual significa que las recetas simplistas generalmente se basan en las experiencias o los rasgos de un tipo de empresario que no se aplican necesariamente a otros (Ronstadt, 1987). Un empresario puede ser emprendedor, pero, por ejemplo, el emprendedor nunca deja de ser innovador, así que no hay unidad de criterios en la definición del término, ni en la caracterización de quien emprende y crea empresa (Gámez, 2008).

\section{Caracterización del emprendedor}

La mayoría de los artículos y libros publicados se enfocan en las características típicas que se deben tener para poder llegar a ser buenos emprendedores (Zorrilla, 2009). Pero, las investigaciones recientes señalan que el emprendimiento no está relacionado con características particulares de la personalidad, sino con una forma de comportamiento que puede ser cambiado y aprendido (Amit y Muller, 1994, citado por Castillo, 1999).

Se puede afirmar que la creatividad no es tan solo una característica de la personalidad, sino que también puede ser vista como un proceso, un producto, incluso como una construcción social (López, 2000), lo cual significa que la actividad creadora debe tener un valor para alguien diferente de la persona creativa (Moncayo, 2008). 
En el contexto de este artículo se define al emprendedor como aquel que mediante un proceso, y teniendo en cuenta los factores endógenos (cualidades, habilidades, conocimiento, experiencia, formación, entre otros) y exógenos (las mutaciones del entorno), lleva a cabo un proyecto, bien sea económico, social, político, ambiental, etcétera. A continuación se presentan estas definiciones y caracterizaciones en seis cuadros, de acuerdo con la clasificación propuesta.

\section{Los clásicos}

La mayoría de historiadores coinciden al afirmar que la economía actual tuvo sus orígenes a comienzos del siglo XVIII en Francia, con los fisiócratas, desprendiéndose de este fenómeno el entrepreneurs, con Richard Cantillon; posteriormente los economistas políticos perfeccionaron la definición de este concepto y complementaron los planteamientos con la innovación y el riesgo (ver tabla 3).

Tabla 3. Aporte de los clásicos

\begin{tabular}{|c|c|c|}
\hline Autor & Definición & Caracterización \\
\hline Richard Cantillon (1680-1734) & $\begin{array}{l}\text { Persona que toma la responsabilidad de poner } \\
\text { en marcha y llevar a término un proyecto (Nue- } \\
\text { no, 2009); persona que toma el riesgo de com- } \\
\text { prar a determinados precios y la venta en pre- } \\
\text { cios inciertos (Stevenson y Jarillo, 1990); persona } \\
\text { que compra los medios de producción a un pre- } \\
\text { cio, los mezcla y vende a otro precio no previsi- } \\
\text { ble cuando combina los factores (Gámez, 2008). }\end{array}$ & $\begin{array}{l}\text { Asume el riesgo, es sumamente in- } \\
\text { teligente (Valdaliso y López, 2.000; } \\
\text { Rodríguez y Jiménez, 2005); no po- } \\
\text { see un retorno seguro, asume y so- } \\
\text { porta los riesgos que dominan el } \\
\text { comportamiento del mercado (For- } \\
\text { michella, 2004). }\end{array}$ \\
\hline Jean-Baptiste Say (1767-1832) & $\begin{array}{l}\text { Protagonista del desarrollo económico en la ac- } \\
\text { tividad en general (Stevenson y Jarillo, 1990); } \\
\text { agente productivo que compra servicios de los } \\
\text { demás agentes, los combina en el proceso pro- } \\
\text { ductivo para generar productos que tengan va- } \\
\text { lor superior a la suma de los servicios utilizados } \\
\text { (Gámez, 2008); individuo líder, previsor, toma- } \\
\text { dor de riesgos y evaluador de proyectos, y que } \\
\text { moviliza recursos desde una zona de bajo rendi- } \\
\text { miento a una de alta productividad (Formichella, } \\
\text { 2004); agente que reúne y combina los medios } \\
\text { de producción (recursos naturales y recursos fi- } \\
\text { nancieros) para constituir un ente productivo, y } \\
\text { encuentra en el valor recibido de los productos } \\
\text { la recuperación del capital que emplea y la utili- } \\
\text { dad que busca (Varela, 2001). }\end{array}$ & \begin{tabular}{|l} 
\\
Trabajador superior (Rodríguez y Ji- \\
ménez, 2005); el beneficio repre- \\
senta un premio por la asunción de \\
riesgos (Valdaliso y López, 2000).
\end{tabular} \\
\hline Adam Smith (1723-1790) & $\begin{array}{l}\text { Identifica al emprendedor como business mana- } \\
\text { gement para hacer referencia a las "fuerzas exter- } \\
\text { nas" (Formichella, 2004). }\end{array}$ & $\begin{array}{l}\text { Trabajador superior, innovador (Ro- } \\
\text { dríguez y Jiménez, 2005). }\end{array}$ \\
\hline J. H. von Thunen (1783-1850) & $\begin{array}{l}\text { Persona que toma decisiones sobre la base de lo } \\
\text { complicado del riesgo, y el ingenio usado (Rodrí- } \\
\text { guez y Jiménez, 2005). }\end{array}$ & $\begin{array}{l}\text { Toma el riesgo, es sumamente inte- } \\
\text { ligente (Rodríguez y Jiménez, 2005). }\end{array}$ \\
\hline $\begin{array}{l}\text { H. K. von Mangoldt (1824- } \\
\text { 1868) }\end{array}$ & $\begin{array}{l}\text { Entendida como renta de la capacidad o el talen- } \\
\text { to (Valdaliso y López, 2000). }\end{array}$ & $\begin{array}{l}\text { Innovador (Rodríguez y Jiménez, } \\
\text { 2005). }\end{array}$ \\
\hline
\end{tabular}


Esta concepción del emprendedor continuó hasta comienzos del siglo XX; sin haber consenso en la definición y caracterización de los clásicos, pero en términos generales — sin que esto reduzca todos los aportes - se le puede resumir como la persona que crea empresas asumiendo riesgos.

\section{Los neoclásicos}

Las ideas de los neoclásicos empiezan a principio del siglo $\mathrm{XX}$, destacándose el autor alemán Max Weber, quien analiza la actuación del emprendedor en la economía en su ensayo La ética protestante y el espiritu del capitalismo, además de otros autores que surgieron con el florecimiento de la economía estadounidense, como Francis Walter, Frederick Hawley, John Bates Clark y Frank Knight (ver tabla 4).

Tabla 4. Aporte de los neoclásicos

\begin{tabular}{|c|c|c|}
\hline Autor & Definición & Caracterización \\
\hline Max Weber (1864-1920) & $\begin{array}{l}\text { Sujeto con una ética, una mentalidad y un código } \\
\text { de conducta diferente, que le impulsa a la frugalidad } \\
\text { en busca de la multiplicación de su riqueza, trans- } \\
\text { formando así su actividad en una profesión de vida, } \\
\text { guiada por una moral puritana (Rodríguez y Jimé- } \\
\text { nez, 2005). }\end{array}$ & $\begin{array}{l}\text { Líder superior (carismático), trabajador superior } \\
\text { (Rodríguez y Jiménez, 2005). }\end{array}$ \\
\hline Alfred Marshall (1842-1924) & $\begin{array}{l}\text { Poseedor de caracteres y retribuciones propias del } \\
\text { capitalista y de trabajador cualificado (gerente) (Val- } \\
\text { daliso y López, 2000); es el elemento que dirige la or- } \\
\text { ganización, líder por naturaleza, que está dispuesto } \\
\text { a actuar bajo las condiciones de incertidumbre que } \\
\text { causa la ausencia de información completa (Formi- } \\
\text { chella, 2004). }\end{array}$ & $\begin{array}{l}\text { Líder superior (carismático) (Rodríguez y Jimé- } \\
\text { nez, 2005); una persona puede aprender y ad- } \\
\text { quirir habilidades para ser emprendedora (Formi- } \\
\text { chella, 2004). }\end{array}$ \\
\hline John M. Keynes (1883-1946) & $\begin{array}{l}\text { Continúa con la doctrina marshaliana en lo referen- } \\
\text { te a considerar al emprendedor como un trabajador } \\
\text { superior y expone el concepto original de animal } \\
\text { spirits —o impulso espontáneo a la acción- (Rodrí- } \\
\text { guez y Jiménez, 2005). }\end{array}$ & $\begin{array}{l}\text { Líder superior, (carismático), actor espontáneo } \\
\text { (Rodríguez y Jiménez, 2005). }\end{array}$ \\
\hline Francis Walter (1840-1897) & $\begin{array}{l}\text { Sigue con los postulados marshalianos consideran- } \\
\text { do a la persona como tomadora de riesgo y en cali- } \\
\text { dad de liderazgo (Rodríguez y Jiménez, 2005). }\end{array}$ & $\begin{array}{l}\text { Acentuó los elementos de toma de decisiones y } \\
\text { el líder superior (Rodríguez y Jiménez, 2005). }\end{array}$ \\
\hline $\begin{array}{l}\text { Frederick Hawley (1843- } \\
\text { 1929) }\end{array}$ & $\begin{array}{l}\text { Reiteró la vieja doctrina de Cantillon, al considerar a } \\
\text { la persona como tomadora de riesgo, pero hizo én- } \\
\text { fasis en la importancia del emprendedor en el cre- } \\
\text { cimiento económico (Rodríguez y Jiménez, 2005). }\end{array}$ & Tomador de riesgo (Rodríguez y Jiménez, 2005). \\
\hline Bates Clark (1847-1938) & $\begin{array}{l}\text { Es la persona coordinadora de la actividad eco- } \\
\text { nómica (Rodríguez y Jiménez, 2005). }\end{array}$ & $\begin{array}{l}\text { No es tomadora de riesgo (Rodríguez y Jiménez, } \\
\text { 2005). }\end{array}$ \\
\hline Frank Knight (1885-1897) & $\begin{array}{l}\text { Es la persona que percibe los riesgos asegurables y } \\
\text { la incertidumbre no asegurable, tomando una deci- } \\
\text { sión sobre las ganancias que relaciona a la incerti- } \\
\text { dumbre (Rodríguez y Jiménez, 2005). }\end{array}$ & $\begin{array}{l}\text { No es tomadora de riesgo (Rodríguez y Jiménez, } \\
\text { 2005); las capacidades son innatas — su conoci- } \\
\text { miento mejora con el aprendizaje de la experien- } \\
\text { cia-y no son susceptibles de ser comercializa- } \\
\text { das (Valdaliso y López, 2000); toma de decisiones } \\
\text { bajo riesgo con la ausencia de las cualidades de la } \\
\text { imaginación y la audacia (Kirzner, 1997). }\end{array}$ \\
\hline
\end{tabular}


A pesar del esfuerzo realizado por los eruditos durante este periodo, fue muy poco el avance realizado al aporte de la definición y caracterización del emprendedor; al igual que con los clásicos, no se llegó a un acuerdo en general, pero, en resumen, sin que esto reduzca todos los aportes, se continúa con la visión de trabajador superior, tomador de riesgo, con especial diferencia en los riesgos asegurables; autores como Clark y Knight consideran que el emprendedor no es tomador de riesgos, porque los asegura o transfiere.

\section{La escuela de Schumpeter}

Joseph Schumpeter, economista austro-estadounidense, fue ministro de Finanzas en Austria, entre 1919 y 1920; profesor de la Universidad de Harvard desde 1932, hasta su fallecimiento en 1950. Habló de las fuerzas que generan inestabilidad o desequilibrio en los mercados, de acuerdo con el concepto de destrucción creativa, como forma para describir el proceso de transformación que acompaña las innovaciones (ver tabla 5).

Tabla 5. Aporte de Joseph Schumpeter

\begin{tabular}{|c|c|c|}
\hline Autor & Definición & Caracterización \\
\hline $\begin{array}{l}\text { Joseph Alois } \\
\text { Schumpeter } \\
(1883-1950)\end{array}$ & $\begin{array}{l}\text { Persona extraordinaria que promueve nuevas } \\
\text { combinaciones o innovaciones, no obstante, sus } \\
\text { actividades generan inestabilidades en los mer- } \\
\text { cados (Schumpeter, 1950; Valdaliso y López, 2000; } \\
\text { Ocampo, 2008; Formichella, 2004; González et al., } \\
\text { 2010); persona con idea de negocio, el innovador, } \\
\text { el que pone las ideas en movimiento, haciéndolas } \\
\text { poderosas y potencialmente rentables - destruc- } \\
\text { ción creativa- (Rodríguez y Jiménez, 2005); indi- } \\
\text { viduo iniciador del cambio y generador de nue- } \\
\text { vas oportunidades (Castillo, 1999; Mccaffrey, 2009); } \\
\text { persona que perturba el equilibrio del mercado } \\
\text { con su innovación (Stevenson y Jarillo, 1990); no } \\
\text { es un inventor, aunque puede explotar una inven- } \\
\text { ción; tampoco es un capitalista (quien presta fon- } \\
\text { dos al emprendedor), mas sí asigna recursos, toma } \\
\text { decisiones y organiza innovadoramente la activi- } \\
\text { dad económica (Nueno, 2009); innova mediante } \\
\text { la introducción de nuevos productos o la mejo- } \\
\text { ra de productos existentes, con la introducción de } \\
\text { nuevos métodos de producción, la apertura de un } \\
\text { nuevo mercado, el acceso a una nueva fuente de } \\
\text { abastecimiento para materias o productos semie- } \\
\text { laborados, e incluso mediante la creación de nue- } \\
\text { vas formas de organización o estructuración de la } \\
\text { actividad económica, incluyendo la organización } \\
\text { de un monopolio (Goss, 2005; Nueno, 2009). }\end{array}$ & $\begin{array}{l}\text { Posee aptitudes fuera de las actividades ru- } \\
\text { tinarias que están presentes solo en una } \\
\text { pequeña fracción de la población, para } \\
\text { producir un nuevo producto o uno viejo de } \\
\text { una nueva manera (Schumpeter, 1950; Kirz- } \\
\text { ner, 1973, 1999; Formichella, 2004; González } \\
\text { et al., 2010); posee capacidades para resol- } \\
\text { ver problemas y tomar decisiones, su tarea } \\
\text { consiste en romper con la tradición y cons- } \\
\text { truir una nueva forma de interpretar las in- } \\
\text { teracciones (Ocampo, 2008); se caracteriza } \\
\text { por realizar nuevas combinaciones (Valdali- } \\
\text { so y López, 2000); es brillante, imaginativo, } \\
\text { innovador, atrevido, Ileno de recursos (Mc- } \\
\text { caffrey, 2009); le da importancia a la volun- } \\
\text { tad individual y la motivación, a la capaci- } \\
\text { dad de alterar el statu quo económico por } \\
\text { medio de innovaciones (Goss, 2005); más } \\
\text { que la creatividad o la invención, es volver- } \\
\text { la realidad al llevarla al mercado, vencer las } \\
\text { dificultades del entorno y, sobre todo, lo- } \\
\text { grar el éxito continuo y prolongado, todo } \\
\text { esto está asociado al liderazgo (Varela, 2001; } \\
\text { Ocampo, 2008). }\end{array}$ \\
\hline
\end{tabular}


En resumen, se puede afirmar que, aunque Schumpeter no desarrolla propiamente una teoría sobre el emprendimiento, introduce un elemento importante como es la innovación, la cual involucra algo más que creatividad o invención; de esta forma se crea la diferenciación entre el emprendedor, el inventor y el capitalista, el emprendedor como alguien innovador más que inventor y que quien financia el proyecto.

\section{La escuela austriaca}

Actualmente el pensamiento de la escuela austriaca es mucho más conocido que en la época en la cual se produjo la revolución marginalista, a fines del siglo XIX, debido en parte al idioma alemán y a la persecución nazi que obligó a las principales figuras a abandonar Viena, a mediados de 1930. Y si bien es cierto que Carl Menger fundó la Escuela Austríaca de Economía, fue con Ludwig von Mises con quien empezó a perfeccionarse el término emprendedor; más tarde el máximo representante de esta escuela fue su alumno Israel Kirzner (ver tabla 6).

Tabla 6. Aporte de la escuela austriaca

\begin{tabular}{|c|c|c|}
\hline Autor & Definición & Caracterización \\
\hline $\begin{array}{l}\text { Ludwig von } \\
\text { Mises (1881- } \\
1973)\end{array}$ & $\begin{array}{l}\text { Aquel que desea especular } \\
\text { en una situación de incerti- } \\
\text { dumbre, respondiendo a las } \\
\text { señales del mercado con res- } \\
\text { pecto a precios, ganancias y } \\
\text { pérdidas (Kirzner, 1997; Casti- } \\
\text { Ilo, 1999; González et al., 2010). }\end{array}$ & $\begin{array}{l}\text { Cualidades de imaginación, audacia y sorpresa (Kirzner, 1997); debe } \\
\text { poseer tres características esenciales: ser evaluador (calcular benefi- } \\
\text { cios y costos), ser empresario (construir decisiones para utilizar los fac- } \\
\text { tores), y "soportar" la incertidumbre (Formichella, 2004); el factor em- } \\
\text { prendedor está presente en todas las acciones humanas debido a las } \\
\text { incertidumbres presentes en el contexto de estas acciones, y no se li- } \\
\text { mita a las acciones de un tipo particular de personas (González et al., } \\
\text { 2010). }\end{array}$ \\
\hline $\begin{array}{l}\text { Freidrich Ha- } \\
\text { yek (1899- } \\
\text { 1992) }\end{array}$ & $\begin{array}{l}\text { Aquel participante del mer- } \\
\text { cado que adquiere una me- } \\
\text { jor información que le per- } \\
\text { mite reconocer y aprovechar } \\
\text { oportunidades (Kirzner, 1997). }\end{array}$ & $\begin{array}{l}\text { Siempre está listo para la sorpresa, dispuesto a tomar las medidas que } \\
\text { le permitan beneficiarse de estas sorpresas; genera acciones especu- } \\
\text { lativas en las que ve oportunidades de ganancia, las decisiones puede } \\
\text { corregirlas como resultado del descubrimiento (conocimiento) de un } \\
\text { antiguo error, cada uno de estos descubrimiento es acompañado por } \\
\text { un sentido de sorpresa (Kirzner, 1997); ágil, captador y utilizador de in- } \\
\text { formación, lo cual le lleva a encontrar oportunidades (Nueno, 2009). }\end{array}$ \\
\hline $\begin{array}{l}\text { Israel Kirzner } \\
\text { (1930-) }\end{array}$ & $\begin{array}{l}\text { Aquel sujeto que descubre } \\
\text { en el mundo de conocimien- } \\
\text { to imperfecto una oportuni- } \\
\text { dad que otros no han percibi- } \\
\text { do (Kirzner, 1997, 1999). }\end{array}$ & $\begin{array}{l}\text { Capacidad de percibir nuevas oportunidades que otros no hayan no- } \\
\text { tado, es la habilidad para ver cuándo un nuevo producto tiene un va- } \\
\text { lor inimaginado para el cliente, y cuándo un nuevo método de pro- } \\
\text { ducción es desconocido para los demás (Kirzner, 1973; Castillo, 1999; } \\
\text { Rodríguez y Jiménez, 2005; González et al., 2010); darse cuenta de la } \\
\text { alerta (el "descubrimiento"), de los errores que se han producido, pasar } \\
\text { a tomar ventaja de estos descubrimientos y fortalecer así el mercado } \\
\text { de forma sistemáticamente equilibradora (Kirzner, 1997, 1999; Castillo, } \\
\text { 1999; González et al., 2010); del estado de alerta se derivan oportuni- } \\
\text { dades hasta ahora inadvertidas (Kirzner, 1973); tiene un conocimiento } \\
\text { superior de las imperfecciones del mercado, que utiliza para su venta- } \\
\text { ja (Stevenson y Jarillo, 1990); permanece alerta a los cambios y condi- } \\
\text { ciones del mercado, anticipándolas de la mejor manera posible (Rodrí- } \\
\text { guez y Jiménez, 2005). }\end{array}$ \\
\hline
\end{tabular}


En resumen, se defiende el equilibrio que genera el emprendedor en el mercado al lograr mejorar y hacer más eficiente la red comercial, anular las turbulencias y crear nuevas riquezas, caracterizándose por su estado de alerta a las oportunidades. Kirzner manifiesta que sus planteamientos se complementan con los de Schumpeter.

Otras escuelas de pensamiento, según Fonrouge (2002)

El American Journal of Small Business en presentó 1988 una amplia discusión sobre la función del emprendedor, siendo este un punto de partida para reconocer la complejidad y variedad de su análisis. Resultado de esto fue el aporte de investigadores críticos con relación al tema de las escuelas de pensamiento empresarial. Esto es retomado por Fonrouge (2002), citado por Rodríguez y Jiménez (2005), quien destaca cuatro corrientes: la comportamental, la psicológica (cognitiva), la económica y la de procesos, sin desconocer lo que aportan otros autores (ver tabla 7).

Tabla 7. Aportes de las escuelas del pensamiento según Fonrouge (2002)

\begin{tabular}{|c|c|c|}
\hline Escuela & Definición & Caracterización \\
\hline $\begin{array}{l}\text { Escuela psicológica } \\
\text { con las corrientes } \\
\text { personalistas y } \\
\text { cognitivas }\end{array}$ & $\begin{array}{l}\text { Se define por un cierto número de atri- } \\
\text { butos psicológicos descritos tanto por la } \\
\text { personalidad como por los procesos cog- } \\
\text { nitivos activados por las circunstancias } \\
\text { (Shaver y Scott, 1991; Rodríguez y Jimé- } \\
\text { nez, 2005). }\end{array}$ & $\begin{array}{l}\text { Las características personológicas se han desa- } \\
\text { creditado, pero se requiere una persona en cuya } \\
\text { mente todas las posibilidades se junten, que crea } \\
\text { que la innovación es posible, y que tenga la moti- } \\
\text { vación para persistir hasta que el trabajo esté he- } \\
\text { cho (Shaver y Scott, 1991). }\end{array}$ \\
\hline $\begin{array}{l}\text { Escuela } \\
\text { comportamental }\end{array}$ & $\begin{array}{l}\text { Se define por el conjunto de actividades } \\
\text { que se ponen en marcha para crear una or- } \\
\text { ganización (Gartner, 1988; Rodríguez y Ji- } \\
\text { ménez, 2005). }\end{array}$ & $\begin{array}{l}\text { Presentan necesidades de cumplimiento y de de- } \\
\text { pendencia, un gusto por el riesgo y un sentimien- } \\
\text { to por controlar su destino en algunas ocasio- } \\
\text { nes más enmarcados que en los administradores } \\
\text { (Gartner, 1988; Rodríguez y Jiménez, 2005). }\end{array}$ \\
\hline Escuela económica & $\begin{array}{l}\text { Se especializa en la toma de decisiones } \\
\text { pensadas, relativas a la coordinación de re- } \\
\text { cursos escasos (Casson, 1991, citado por Ro- } \\
\text { dríguez y Jiménez, 2005), que son el resul- } \\
\text { tado de un juicio, es decir, los resultados de } \\
\text { las decisiones dependen de quien las toma } \\
\text { (Casson, 1982, citado por Nueno, 2009). }\end{array}$ & $\begin{array}{l}\text { Se requiere que las personas tengan diferentes } \\
\text { conceptos acerca del valor de los recursos, por- } \\
\text { que deben tener el control sobre estos (los cua- } \\
\text { les intervienen en el proceso de producción de } \\
\text { un nuevo producto o servicio) para hacer que la } \\
\text { oportunidad sea rentable (Casson, 1982, citado } \\
\text { por Shane y Venkataraman, 2000). }\end{array}$ \\
\hline Escuela de procesos & $\begin{array}{l}\text { Es aquel que desarrolla oportunidades y } \\
\text { crea una organización para explotarlas (By- } \\
\text { grave y Hofer, 1991; Rodríguez y Jiménez, } \\
\text { 2005), sin preocuparse por los recursos que } \\
\text { en aquel momento él mismo controla (Ho- } \\
\text { fer, } 1988 \text { citado por Nueno, 2009). }\end{array}$ & $\begin{array}{l}\text { Algunas de las características importantes son las } \\
\text { de iniciar con un acto de voluntad humana, en- } \\
\text { contrarse en un ámbito de la empresa individual; } \\
\text { dar un cambio de estado, una discontinuidad, un } \\
\text { proceso holístico, dinámico, único; numerosas va- } \\
\text { riables antecedentes y sus resultados son extre- } \\
\text { madamente sensibles a las condiciones iniciales } \\
\text { de estas variables (Bygrave y Hofer, 1991). }\end{array}$ \\
\hline
\end{tabular}

Tomado de Fonrouge (2002), citado por Rodríguez y Jiménez (2005, p. 83). 
En resumen, la escuela psicológica proporciona cierto número de atributos psicológicos descritos tanto por la personalidad como por los procesos cognitivos; la escuela comportamental presenta un conjunto de actividades que al ponerse en marcha crean una organización; la escuela económica se basa en la toma intuitiva de decisiones pensadas, relativas a la coordinación de recursos; y la escuela de procesos muestra cómo se desarrollan las oportunidades a fin de crear una organización para ser aprovechadas.

\section{Aportes generales de otros autores}

Los anteriores planteamiento, resultan "insuficiente" para explicar todo lo referente al emprendedor y su actividad, es por esto que se recopilan en la tabla 8 algunos aportes realizados por otros autores en el tema del emprendimiento, desde investigaciones empírica hasta otras más teóricas, todo esto con el propósito de construir un cuerpo teórico más nutrido alrededor del emprendedor.

Tabla 8. Aportes generales de otros autores

\begin{tabular}{|l|l|l|l|}
\hline \multicolumn{1}{|c|}{ Autor } & \multicolumn{1}{|c|}{ Contribución } & \multicolumn{1}{c|}{ Autor } & \multicolumn{1}{c|}{ Contribución } \\
\hline $\begin{array}{l}\text { Investigaciones } \\
\text { de percepciones } \\
\text { ejecutivas }\end{array}$ & $\begin{array}{l}\text { Las investigaciones de percep- } \\
\text { ciones de los ejecutivos descri- } \\
\text { ben al emprendedor con térmi- } \\
\text { nos como: innovador, flexible, } \\
\text { dinámico, capaz de asumir ries- } \\
\text { gos, creativo y orientado al cre- } \\
\text { cimiento (Castillo, 1999; Gonzá- } \\
\text { lez et al., 2010). }\end{array}$ & $\begin{array}{l}\text { La prensa popular también ha escrito } \\
\text { extensamente acerca de las especiales } \\
\text { "características psicológicas de los em- } \\
\text { presarios", generalmente se le entiende } \\
\text { como alguien que comienza su negocio } \\
\text { particular con éxito, lo que algunos no } \\
\text { hacen (Stevenson y Jarillo, 1990; Castillo, } \\
\text { 1999; González et al., 2010). }\end{array}$ \\
\hline William Baumol & $\begin{array}{l}\text { Es identificar nueva ideas y po- } \\
\text { nerlas en marcha. Es la persona } \\
\text { que lidera y es fuente de inspi- } \\
\text { ración en el desarrollo de una } \\
\text { nueva empresa (Varela, 2001). }\end{array}$ & $\begin{array}{l}\text { John Hornaday y y Aboud } \\
\text { John }\end{array}$ & $\begin{array}{l}\text { Hombre o mujer que empiezan y desa- } \\
\text { rrollan un negocio donde antes no exis- } \\
\text { tía (Varela, 2001). }\end{array}$ \\
\hline $\begin{array}{l}\text { Orvis Collins y David G. } \\
\text { Moore }\end{array}$ & $\begin{array}{l}\text { Es el hombre que ha creado de } \\
\text { la nada una organización (Vare- } \\
\text { la, 2001). }\end{array}$ & $\begin{array}{l}\text { Es la guía, la integración, y el inicio de } \\
\text { la fuerza, en otras palabras, es el con- } \\
\text { trol de la producción (Kirzner, 1973; Va- } \\
\text { rela, 2001). }\end{array}$ \\
\hline
\end{tabular}

(continúa) 
Tabla 8. Aportes generales de otros autores (continuación)

\begin{tabular}{|c|c|c|c|}
\hline Autor & Contribución & Autor & Contribución \\
\hline \multirow{3}{*}{$\begin{array}{l}\text { Global } \\
\text { Entrepreneurship } \\
\text { Monitor - GEM² } \\
\text { Colombia Caribe } 2010\end{array}$} & \multirow{3}{*}{$\begin{array}{l}\text { El GEM utiliza tres tipologías } \\
\text { para los emprendedores de } \\
\text { acuerdo con la Nueva Activi- } \\
\text { dad Empresarial (TEA): empren- } \\
\text { dedores potenciales, empre- } \\
\text { sarios nacientes y nuevos em- } \\
\text { presarios. Los emprendedores } \\
\text { se caracterizan en su gran ma- } \\
\text { yoría por ser hombres, jóvenes } \\
\text { de } 25 \text { a } 34 \text { años, con educación } \\
\text { secundaria completa, ingre- } \\
\text { sos bajos; reciben información } \\
\text { o experiencia de una perso- } \\
\text { na cercana; participan en redes } \\
\text { de emprendimiento; son inno- } \\
\text { vadores, atentos a las oportu- } \\
\text { nidades, tomadores de riesgos } \\
\text { y que consideran que la crea- } \\
\text { ción de empresas es la "carre- } \\
\text { ra" ideal. }\end{array}$} & $\begin{array}{l}\text { Ley } 1014 \text { de } \\
\text { 2006, Colombia. }\end{array}$ & $\begin{array}{l}\text { Es una persona con capacidad de inno- } \\
\text { var, entendida esta como la capacidad } \\
\text { de generar bienes y servicios de una for- } \\
\text { ma creativa, metódica, ética, responsa- } \\
\text { ble y efectiva. }\end{array}$ \\
\hline & & $\begin{array}{l}\text { Robert D. His- } \\
\text { rich y Michael P. } \\
\text { Peters } \\
\end{array}$ & $\begin{array}{l}\text { Es el procedimiento de crear algo dife- } \\
\text { rente con valor, dedicando los esfuer- } \\
\text { zos y el tiempo necesarios; asimilando } \\
\text { los riesgos financieros, físicos y sociales; } \\
\text { recibiendo las recompensas monetarias } \\
\text { y la satisfacción personal del éxito (Va- } \\
\text { rela, 2001). }\end{array}$ \\
\hline & & Daniel Goleman & $\begin{array}{l}\text { Creador de un nuevo concepto aplica- } \\
\text { do al emprendedor, denominado "inte- } \\
\text { ligencia emocional", la cual promueve la } \\
\text { excelencia personal y profesional, niveles } \\
\text { superiores de liderazgo, eficiencia, auto- } \\
\text { conocimiento, autoestima, autocontrol, } \\
\text { compromiso, integridad, habilidades co- } \\
\text { municativas, empatía, iniciativa, adapta- } \\
\text { bilidad y persuasión (Zorilla, 2009). }\end{array}$ \\
\hline
\end{tabular}

2 El Global Entrepreneurship Monitor (GEM) es un proyecto de investigación que se realiza a través de un consorcio internacional de investigadores con el fin de monitorear la actividad de creación de empresas en los países que de él hagan parte. En 2010 el proyecto contó con representantes de 59 países de los cinco continentes. En Colombia, el reporte GEM Colombia Caribe 2010 se realiza mediante un convenio entre la Universidad del Norte, la Universidad de Cartagena, la Fundación Universitaria Tecnológico Comfenalco, Coosalud Cartagena, Comfenalco Cartagena, la Corporación Universitaria del Caribe (Cecar) y Universidad de Magdalena. Colombia se vinculó a GEM a partir de 2006, con la creación de un equipo integrado por las universidades Andes, Icesi, Javeriana-Cali y Norte.

\begin{tabular}{|c|c|c|c|}
\hline Autor & Contribución & Autor & Contribución \\
\hline $\begin{array}{l}\text { Howard H. } \\
\text { Stevenson }\end{array}$ & $\begin{array}{l}\text { Define al emprendedor como "un individuo } \\
\text { que persigue la oportunidad sin tener en cuen- } \\
\text { ta los recursos que tiene bajo su control" (Vare- } \\
\text { la, 2001); crear una empresa no es suficiente para } \\
\text { ser considerado emprendedor, debe ser innova- } \\
\text { dor no solo en la creación de un nuevo produc- } \\
\text { to, sino, ser creador de una nueva organización o } \\
\text { una nueva forma de producción (Stevenson y Ja- } \\
\text { rillo, 1990; Castillo, 1999; Formichella, 2004). Tie- } \\
\text { ne cono características una sensibilidad especial } \\
\text { para detectar oportunidades y la capacidad de } \\
\text { adentrarse en ellas aun cuando es consciente de } \\
\text { que no dispone de recursos para enfrentarse a la } \\
\text { oportunidad (Nueno, 2009). }\end{array}$ & $\begin{array}{l}\text { Robert } \\
\text { Ronstadt }\end{array}$ & $\begin{array}{l}\text { Individuos que asumen los princi- } \\
\text { pales riesgos en términos de capi- } \\
\text { tal, tiempo y compromiso personal } \\
\text { para proveer valor incremental a sus } \\
\text { productos o servicios que pueden o } \\
\text { no ser nuevos o únicos, pero el va- } \\
\text { lor debe ser de alguna forma infun- } \\
\text { dido por el empresario, consiguien- } \\
\text { do y asignando los recursos y des- } \\
\text { plegando las habilidades necesarias } \\
\text { (Varela, 2001). No se debe buscar un } \\
\text { perfil psicológico determinado, ya } \\
\text { que el empresario está sujeto a los } \\
\text { cambios y cada empresario es úni- } \\
\text { co (Ocampo, 2008). }\end{array}$ \\
\hline
\end{tabular}

(continúa) 
Tabla 8. Aportes generales de otros autores (continuación)

\begin{tabular}{|c|c|c|c|}
\hline Autor & Contribución & Autor & Contribución \\
\hline $\begin{array}{l}\text { David } \\
\text { McClelland }\end{array}$ & $\begin{array}{l}\text { Define al emprendedor como "alguien que ejer- } \\
\text { ce algún control sobre los medios de producción } \\
\text { y produce más de lo que consume a fin de ven- } \\
\text { der este exceso para conseguir un ingreso" (Vare- } \\
\text { la, 2001). Las características del emprendedor son: } \\
\text { un tipo especial de comportamiento e interés por } \\
\text { ocuparse en actividades que implican empren- } \\
\text { der por su prestigio y por su riesgo (Nueno, 2009). }\end{array}$ & Peter Drucker & $\begin{array}{l}\text { Define al entrepreneur como aquel } \\
\text { empresario que es innovador, des- } \\
\text { taca que aunque alguien abra un } \\
\text { pequeño negocio y corra riesgos, } \\
\text { eso no quiere decir que sea innova- } \\
\text { dor y represente un emprendimien- } \\
\text { to (Formichella, 2004; Nueno, 2009). } \\
\text { Traduce la acción empresarial como } \\
\text { una conducta más que un rasgo del } \\
\text { carácter (Varela, 2001). }\end{array}$ \\
\hline $\begin{array}{l}\text { Kirk } \\
\text { Draiheim }\end{array}$ & $\begin{array}{l}\text { Es el iniciador activo de una nueva organización, } \\
\text { quien desempeña un papel básico al empezar la } \\
\text { compañía, administrarla y tener una participación } \\
\text { en ella (Varela, 2001). }\end{array}$ & $\begin{array}{l}\text { Harvey } \\
\text { Leibenstein }\end{array}$ & $\begin{array}{l}\text { Aquel que realiza las actividades } \\
\text { necesarias para crear una empresa } \\
\text { donde los mercados no están es- } \\
\text { tablecidos o definidos y en los cua- } \\
\text { les la función de producción no es } \\
\text { completamente conocida (Varela, } \\
\text { 2001). }\end{array}$ \\
\hline $\begin{array}{l}\text { Albert } \\
\text { Shapero }\end{array}$ & $\begin{array}{l}\text { Define al emprendedor a partir de una serie de } \\
\text { combinaciones de factores, las cuales denomi- } \\
\text { na como el "evento empresarial", siempre y cuan- } \\
\text { do permitan la generación de una nueva empre- } \\
\text { sa, estos eventos son: toma de iniciativa, acumu- } \\
\text { lación de recursos, administración, autonomía } \\
\text { relativa y toma de riesgo (Varela, 2001; Ocampo, } \\
\text { 2008). }\end{array}$ & $\begin{array}{l}\text { Jeffry A. } \\
\text { Timmons } \\
\text { Timmo } \\
\end{array}$ & $\begin{array}{l}\text { Persona con habilidad de crear y } \\
\text { construir algo a partir de casi nada; } \\
\text { es un acto creativo propio del géne- } \\
\text { ro humano (Ocampo, 2008); toma } \\
\text { riesgos calculados y luego hace } \\
\text { todo lo que sea posible para evitar } \\
\text { fallas; percibe oportunidades don- } \\
\text { de otros ven caos; posee conoci- } \\
\text { miento para controlar los recursos } \\
\text { que a menudo son propiedad de } \\
\text { otros (Varela, 2001). }\end{array}$ \\
\hline $\begin{array}{l}\text { Richard T. } \\
\text { Elis y Ralph } \\
\text { H. Hess }\end{array}$ & $\begin{array}{l}\text { Persona o conjunto de personas que toman para sí } \\
\text { la tarea y la responsabilidad de combinar los facto- } \\
\text { res de producción en una organización de negocios } \\
\text { y de mantener la organización en operación; con- } \\
\text { tribuye con su iniciativa, habilidad e ingenio para } \\
\text { planear, organizar y administrar la empresa (Vare- } \\
\text { la,2001). }\end{array}$ & Arthur Cole & $\begin{array}{l}\text { Es la actividad intencional (inclu- } \\
\text { yendo una secuencia lógica de de- } \\
\text { cisiones) de un individuo o de un } \\
\text { grupo de individuos que toman la } \\
\text { iniciativa, mantienen y crecen una } \\
\text { unidad de negocios orientada a la } \\
\text { producción o distribución de bie- } \\
\text { nes y servicios (Varela, 2001). }\end{array}$ \\
\hline Karl Vesper & $\begin{array}{l}\text { Estableció definiciones según diversos profesio- } \\
\text { nales: "para economista, es alguien que reúne re- } \\
\text { cursos, mano de obra, materiales, y otros activos } \\
\text { para generar unos productos de mayor valor me- } \\
\text { diante cambios, innovaciones y nuevos ordena- } \\
\text { mientos; para un empresario, es un competidor } \\
\text { agresivo y una amenaza o un aliado, un cliente, } \\
\text { un proveedor y un gran prospecto de inversión; } \\
\text { para algunos políticos, es un rebelde, descarriado } \\
\text { y muy difícil de controlar; pero, otros lo ven como } \\
\text { una persona que logra que las cosas se hagan; } \\
\text { para un filosofo capitalista, es una persona que } \\
\text { crea riquezas para él y para otros, que encuentra } \\
\text { las mejores formas de utilizar recursos y reducir } \\
\text { desperdicios, alguien que produce trabajos que } \\
\text { otros están felices de conseguir" (Varela, 2001). }\end{array}$ & $\begin{array}{l}\text { Mill } \\
\text { John Stuart } \\
\text { M. }\end{array}$ & $\begin{array}{l}\text { Autor de origen británico, enfati- } \\
\text { zó la importancia del emprendi- } \\
\text { miento para el crecimiento econó- } \\
\text { mico. Expresó que el desarrollo del } \\
\text { entrepreneurship requiere de habi- } \\
\text { lidades no comunes y lamentó la } \\
\text { inexistencia de una palabra en el } \\
\text { idioma inglés que tenga el mismo } \\
\text { significado que el término "entre- } \\
\text { preneur" en francés (Burnett, 2000, } \\
\text { citado por Formichella, 2004; Valda- } \\
\text { liso y López, 2000). }\end{array}$ \\
\hline
\end{tabular}


Luego de presentar estos aportes, se puede afirmar que en general el emprendedor es considerado como una persona creativa, persistente, innovadora, flexible, dinámica, capaz de asumir riesgos, generadora de empleo, transformadora de recursos, entre otras actividades económicas, sociales, ambientales y políticas.

Asimismo, estos aportes indican que las nuevas investigaciones del emprendedor se están preocupando por su entorno y contexto; por la visión holística, sistémica y compleja (escuelas del pensamiento), presentándose como una fortaleza para estas corrientes, lo que permite hablar de responsabilidad social (y otro tipo de emprendedores, como el social, cívico). Todo esto difiere de los primeros pensadores (clásicos, neoclásicos, Schumpeter, austriacos), en el sentido de que su debilidad fue enfocar al emprendedor de forma simplista, solo relacionado con la parte económica y los cambios que este generaba en el mercado.

De los enfoques presentados, el más completo, preciso y confiable es el propuesto por la organización Global Entrepreneurship Monitor (GEM), en el cual un equipo de expertos rinde la evaluación anual sobre las actividades empresariales y las aspiraciones y aptitudes de los individuos en una amplia gama de países. Este estudio es el más grande sobre la dinámica emprendedora en el mundo, revelando las características detalladas relacionadas con la actividad empresarial (www.gemconsortium.org/).

\section{Conclusiones y desafíos}

El emprendimiento como campo de investigación está en proceso de legitimación, pese al gran interés por parte de investigadores de diversas disciplinas, académicos y organizaciones públicas y privadas. Gartner (1988) afirma que por numerosas que sean las investigaciones sobre la persona del emprendedor, ellas son vanas y no contribuyen a su definición, siendo necesario volver al origen, "al estudio de los mecanismos por los cuales se da vida a las organizaciones".

La complejidad del tema no ha permitido que los investigadores se pongan de acuerdo en los conceptos y en una única teoría. Pero, en su conjunto, se complementan una de la otra; por tanto, el emprendedor y el emprendimiento deben verse como un evento contextual en un ecosistema, bajo un pensamiento sistémico que difiere de una persona a otra, de ahí que no se deba buscar una receta mágica que conduzca al éxito.

Esta situación reta a los interesados en el tema a unir esfuerzo con los eruditos de otros campos, en la búsqueda de crear un cuerpo teórico y sistemático de información sobre el emprendimiento, debido a que en estos momentos las investigaciones son empíricas y se requiere mayor soporte teórico. De esta forma, se demuestra a los escépticos que es posible crear las bases teóricas y contrastarlas con investigaciones empíricas.

\section{Referencias}

I. Acs, Z. J. y Audretsch, D. B (2003). Handbook of Entrepreneurship Research, International Handbook Series on Entrepreneurship (2. ${ }^{\mathrm{a}}$ ed.). Nueva York, NY: Kluwer Academic Publishers. 
2. Aktouf, O. (2009). La administración, entre tradición y renovación (4. ${ }^{\mathrm{a}}$ ed.). Cali: Artes Gráficas del Valle.

3. Amorós, L. (2011). El Proyecto Global Entrepreneurship Monitor (GEM). Una aproximación desde el contexto latinoamericano. Revista Latinoamericana de Administración, 46, 1-15.

4. Bygrave, W. y Hofer, C. (1991). Theorizing about entrepreneurship, Entrepreneurship Theory and Practice, 13-22.

5. Cable, D. y Shane, S. (1997, enero). A Prisoner's Dilemma Approach to Entrepreneur-Venture Capitalist Relationships. The Academy of Management Review, 22(1), 142-176.

6. Castillo, A. (1999). Estado del arte en la enseñanza del emprendimiento. Programa Emprendedores como creadores de riqueza y desarrollo regional Intec. Chile: Intec.

7. Díaz, J.; Urbano, D. y Hernández, R. (2005). Teoría económica institucional y creación de empresas. Investigaciones Europeas de Dirección y Economía de la Empresa, 11(3), 209-230.

8. Flor, G. y Lara, A. (2012). Diagnóstico del capital emprendedor y su influencia en la creación de empresas y desarrollo socioeconómico en la región sierra-centro del Ecuador. XXII Congreso Latinoamericano sobre Espiritu Empresarial. Quito, Ecuador: Universidad Andina Simón Bolívar.

9. Formichella, M. (2004). El concepto de emprendimiento y su relación con la educación, el empleo y el desarrollo local. Buenos Aires, Argentina: Publicación INTA.

ı. Gartner, W. (1985, octubre). A Conceptual Framework for Describing the Phenomenon of New Venture Creation. The Academy of Management Review, 10(4), 696-706.
I I. Gartner, W. (1988). "Who is an entrepreneur" is the wrong question. Entrepreneurship Theory and Practice, 47-67.

I2. Gámez, J. (enero-junio de 2008). El emprendedor, hacia una nueva caracterización en Colombia. Management. Revista de la Facultad de Ciencias Empresariales, XVII(29), 17-32.

I3. Global Entrepreneurship Monitor (GEM) Colombia Caribe 2010. Reporte de resultados GEM Colombia Caribe 2010.

I4. González, J. et al. (2010). Caracterización emprendedora de los empresarios en los valles de Tundama y Sugamuxi, Boyacá (Colombia). Pensamiento \& Gestión, 29, 163-189.

I 5. Goss, D. (2005). Schumpeter's Legacy? Interaction and Emotions in the Sociology of Entrepreneurship. Entrepreneurship. Theory and Practice, 205-218.

I6. Grégoire, D.; Corbett, A. y McMullen, J. (septiembre de 2011). The Cognitive Perspective in Entrepreneurship: An Agenda for Future Research. Journal of Management Studiesk, 48(6), 14431477.

I7. Gupta, V. K. et al. (2012, 12 de mayo). Institutional environment for entrepreneurship in rapidly emerging major economies: the case of Brazil, China, India, and Korea. Springer, Int Entrep Manag J. DOI 10.1007/s11365-0120221-8.

I 8. Haque, M. S. (2004). Reforming Public Administration in Southeast Asia: Trends and Impacts. A Global Journal, 4, 361-371.

I9. Kent, C. (primavera de 1989). The Treatment of Entrepreneurship in Principles of Economics Textbooks. The Journal of Economic Education, 20(2), 153-164. 
20. Kirzner, I. (1973). Competition and Entrepreneurship. Londres, Reino Unido: The University of Chicago Press.

2 I. Kirzner, I. (1997). Entrepreneurial Discovery and the Competitive Market Process: An Austrian Approach. Journal of Economic Literature, 35(1), 6085.

22. Kirzner, I. (1999). Creativity and/or Alertness: A Reconsideration of the Schumpeterian Entrepreneur. Review of Austrian Economics, 11, 5-17.

23. Kshetri, N. y Dholakia, N. (2011). Regulative institutions supporting Entrepreneurship in emerging economies: A comparison of China and India. J Int Entrep, 110-132. DOI 10.1007/s10843010-0070-x.

24. Kuskova, V.; Podsakoff, N. y Podsakoff, P. (2011). Effects of theoretical contribution, methodological rigor, and journal quality, on the impact of scale development articles in the field of entrepreneurship. Strategic Entrepreneurship Journal, 5, 10-36.

25. República de Colombia, Ministerio de Comercio, Industria y Turismo (2006). Ley 1014, De fomento a la cultura del emprendimiento.

26. Lounsbury, M. y Glynn, M. (2001, junio-julio). Cultural Entrepreneurship: Stories, Legitimacy, and the Acquisition of Resources. Strategic Management Journal, 22(6-7), 545-564.

27. Lu, Y. et al. (2008). Knowledge management and innovation strategy in the Asia Pacific: Toward an institution-based view. Asia Pacific J Manage 25, 361374.

28. Matiz, F. (2009, mayo-agosto). Investigación en emprendimiento, un reto para la construcción de conocimiento. Revista EAN, 66, 169-182.
29. Mccaffrey, M. (2009). Entrepreneurship, economic evolution, and the end of capitalism: reconsidering schumpeter's thesis. The quarterly journal of austrian economics, 12(4), 3-21.

30. Mello et al. (2011, marzo-abril). A Dimensão Histórica dos Discursos acerca do Empreendedor e do Empreendedorismo. $R A C$, Curitiba, 15(2), 179-197.

3 I. Milton, J. (2001). The Role of SMEs in Commercialising University Research \& Development: The Asia-Pacific Experience. Small Business Economics 16, 141-148.

32. Moncayo, P. (2008, enero-junio). Emprendimiento: un concepto que integra el ser y el hacer del sujeto. Management, Revista de la Facultad de Ciencias Empresariales, XVII(29), 33-48.

33. Murphy, A. (abril de 1995). Economic Regionalization and Pacific Asia. Geographical Review, 85(2), 127-140.

34. Murphy, P. (2009). Entrepreneurship theory and the poverty of historicism. Journal of Management History, 15(2), 109-133.

35. Nueno, P. (2009). Emprendiendo hacia el 2020: una renovada perspectiva global del arte de crear empresas y sus artistas. Deusto.

36. Ocampo, J. (2008, enero-abril). Aproximación conceptual a la preparación en emprendimiento. Eos, 2, 33-53.

37. Phan, P.; Zhou, J. y Abrahamson, E. (2010). Entrepreneurship in China. Management and Organization, USA, 175-194.

38. Pleggenkuhle-Miles, E. et al. (2007). The adolescence of Asia management research: APJM, 1997-2006. Asia Pacific J Manage, 24, 467-489. DOI 10.1007/s10490-007-9058-z.

39. Praag, C. M. van y Versloot, P. H. (2007). What is the value of 
entrepreneurship? A review of recent research. Small Business Economy, 351382.

40. Reynolds, P. D. et al. (2005). Global Entrepreneurship Monitor: Data Collection Design and Implementation 1998-2003. Small Business Economics, 24, 205-231.

4I. Rodríguez, C. y Jiménez, M. F. (2005). Emprenderismo, acción gubernamental y academia. Revisión de la literatura. Innovar, 15(26), 73-89.

42. Rodríguez, A. (2008, julio-diciembre). El emprendimiento en Colombia. Entramado, 4(2), 20-37.

43. Ronstadt, R. (1987). The Educated Entrepreneurs: A New Era of Entrepreneurial Education is Beginning. American Journal of Small Business, 37-53.

44. Shapero, A. (1985, octubre). Why entrepreneurship? A worldwide perspective. Journal of Small Business Management, 1-5.

45. Shane, S. y Venkataraman, S. (2000). The Promise of Entrepreneurship as a Field of Research. The Academy of Management Review, 25(1), 217-226.

46. Shane, S. et al. (2003). Entrepreneurial motivation. Human Resource Management Review 13, 257-279.

47. Shaver, K. y Scott, L. (1991). Person, Process, Choice: The psychology of new venture creation. Entrepreneurship: Theory and Practice, 23-45.

48. Sánchez, J. y Gutiérrez, A. (2011). Entrepreneurship research in Spain: Developments and distinctiveness. Psicothema, 23(3), 458-463.

49. Schumpeter, J. (1950). Capitalis, Socialism and Democracy. Nueva York, NY: Harper \& Row, Publishers.

50. Stevenson, H. H y Jarillo J. C. (1990). A Paradigm of Entrepreneurship:
Entrepreneurial Management. Strategic Management Journal, 11, 17-27.

5 I. Terjesen, S. y Hessels, J. (2009). Varieties of export-oriented entrepreneurship in Asia. Asia Pac J Manag 26, 537-561. DOI 10.1007/s10490-0099138-3.

52. Thornton, P. (1999). The Sociology of Entrepreneurship. Annual Review of Sociology, 25, 19-46.

53. Valdaliso, J. M. y López, S. (2.000). Historia económica de la empresa. Barcelona: Crítica.

54. Varela, R. (2001). Innovación empresarial: arte y ciencia en la creación de empresas. (2.a ed.) Bogotá, Colombia: Pearson Educación.

55. Vera, M. y Mora, E. (2011). Líneas de investigación en micro, pequeñas y medianas empresas. Revisión documental y desarrollo en Colombia. Tendencias, XII(1), 213-226.

56. Wielemaker, M. y Gedajlovic, E. (2011). Governance and capabilities: Asia's Entrepreneurial performance and stock of venture forms. Asia Pac J Manag, 157-185. DOI 10.1007/s10490010-9221-9.

57. Wood, C. (2004). Marketing and e-commerce as tools of development in the Asia-Pacific region: a dual path. International Marketing Review, 21(3), 301-320.

58. Zahra, S. A. y Nambisan, S. (2011). Entrepreneurship in global innovation ecosystems. Academy of Marketing Science Rev., 1, 4-17.

59. Zorrilla, J. (2009). Las etapas del empresario moderno. Buenos Aires, Argentina: El Cid Editor. www.gemconsortium. org/ 